\title{
Quantifying diet-borne metal uptake in Gammarus pulex using stable isotope tracers
}

\author{
Pellet Bastien ${ }^{1}$, Ayrault Sophie ${ }^{2, *}$, Tusseau-Vuillemin Marie-Helene ${ }^{3}$, Gourlay-Francé Catherine ${ }^{1}$
}

${ }^{1}$ IRSTEA, Unité de Recherche Hydrosystèmes et Bioprocédés, 1 rue P.-G. de Gennes, 92731 Antony, France

${ }^{2}$ Laboratoire des Sciences du Climat et de I'Environnement LSCE (CEA-CNRS-UVSQ), UMR 8212, Bât. 12 Av. de la Terrasse, 911198 Gif-sur-Yvette cedex, France

${ }^{3}$ IFREMER, Direction Scientifique, 155 rue Jean-Jacques Rousseau, 92138 Issy les Moulineaux cedex, France

*Corresponding author, Sophie Ayrault, email address : $\underline{\text { sophie.ayrault@lsce.ipsl.fr }}$

\begin{abstract}
:
Gammarids are aquatic amphipods widely used for water quality monitoring. To investigate the copper and cadmium diet-borne metal uptake in Gammarus pulex, we adapted the pulse-chase stable isotopes-based approach to determine the food ingestion rate (IR), the gut retention time (GRT) and the metal assimilation efficiencies (AE). G. pulex were fed with $65 \mathrm{Cu}-, 106 \mathrm{Cd}$-, and $53 \mathrm{Cr}$-labeled alder leaves for $7.5 \mathrm{~h}$ and then with unlabeled leaves for $5 \mathrm{~d}$. The metal stable isotope contents in the gammarids, leaves, filtered water and periodically collected feces were determined. Chromium was poorly assimilated by the gammarids; thus, $\mathrm{Cr}$ was used as an unassimilated tracer. The first tracer defecation occurred before the first feces harvest, indicating a gut passage time of less than $9 \mathrm{~h}$. A 24-h GRT and a $0.69 \mathrm{~g} \mathrm{~g}-1 \mathrm{~d}-1 \mathrm{IR}$ were estimated. The Cd AE value was estimated as $5-47 \%$, depending on the assimilation determination method applied. The $\mathrm{Cu} A E$ value could not be evaluated regardless of the determination method used, most likely because of the rapid $\mathrm{Cu}$ regulation in gammarids in addition to analytical uncertainties when determining the $\mathrm{Cu}$ content in leaves. Application of the $\mathrm{Cd} \mathrm{AE}$ value in the framework of the biodynamic bioaccumulation model shows that the diet-borne uptake of Cd significantly contributes (66-95\%) to the metal bioaccumulation in G. pulex fed with alder leaves.
\end{abstract}

Keywords: Assimilation efficiency, Gammarus pulex, Cadmium, Copper, Biodynamic model, Diet-borne uptake 
41

42

43

44

45

46

47

48

49

\section{1 - Introduction}

The aquatic amphipod genus Gammarus is widely used for water quality monitoring through passive (autochthonous specimens) or active (caged gammarids) approaches (e.g., Besse et al., 2013; Geffard et al., 2010; Khan et al., 2011; Kunz et al., 2010; Sroda and Cossu-Leguille, 2011). Fialkowski et al. (2003) have proven the feasibility of using Gammarus fossarum as a metal biomonitor in a river affected by $\mathrm{Pb}-\mathrm{Zn}$ mining activities. The sensibility of the behavior of gammarids to a metal-polluted environment has also been demonstrated (Dedourge-Geffard O et al., 2009). Gammarus pulex is ubiquitous in European freshwaters.

The leaf litter serves as a main food source for G. pulex that is a key species in metal mobilization in freshwater ecosystems as reviewed by Schaller et al. (2011a). G. pulex is one of the rare crustaceans for which the influence of natural and anthropogenic stressors on the ingestion rate has been investigated (Maltby et al., 2002; Coulaud et al., 2011). Gammarids can accumulate waterborne and diet-borne metals. The waterborne uptake route has been intensively studied (e.g., Bourgeault et al., 2013; Lebrun et al., 2012; Vellinger et al., 2012). Although the diet-borne uptake of metals may be a significant pathway for metal accumulation in gammarids (Abel and Bärlocher, 1988), this type of uptake has been poorly documented. It should be mentioned that tolerance mechanisms, including both avoidance (decrease of feeding rate, food selection) and detoxification (Malty et al., 2002; Schaller et al., 2011b), regulate metals uptake. Khan et al. (2011) have shown that copper uptake is lower for historically impacted populations compared to naïve G. pulex populations. Schaller et al. (2011b) found that G. pulex gut epithelial cells sequester and detoxify metals such as cadmium $(\mathrm{Cd})$ and copper $(\mathrm{Cu})$. 
63

64

65

66

67

68

69

70

71

72

73

74

The in situ contributions of diet-borne and waterborne metals to the total bioaccumulation can be estimated using bioaccumulation models, among which is the biodynamic model validated on field data of the metal body-burden in aquatic (freshwater and marine) invertebrates (Ahlf et al., 2009; Golding et al., 2013). Briefly, according to the biodynamic model, the diet-borne influx of a metal is driven by the food ingestion rate (IR), the metal concentration in the food and the assimilation efficiency (AE). The AE value is defined as the fraction of metal ingested via contaminated food that penetrates across the cells of the gut wall, hence incorporating into the tissues. AE values are commonly used to compare bioavailable metal fractions among various conditions characterized by a range of parameters (e.g., food type and species) (Wang and Fisher, 1999). It has been shown that Cd is assimilated more efficiently by the estuarine amphipod Leptocheirus plumulosus when feeding with sediments compared with feeding with phytoplankton (Schlekat et al., 2000).

The pulse-chase feeding method (a short dietary exposure to metal-contaminated food followed by a depuration phase) has been proposed to determine AE values in the laboratory (Calow and Fletcher, 1972). The use of tracers (radiotracers or stable isotopes) is necessary to discriminate the added amounts of metals from the background level. After complete excretion of the labeled food, the organisms are sacrificed and the AE values are estimated from the comparison of the amount of tracers accumulated in the organisms and the amount of tracers in the ingested food (or in the feces, providing that a mass balance of the target contaminants can be settled on the system). Alternatively, the AE values can be calculated using relevant tracer ratios in the food and feces only, providing that the food is dually labeled with an unassimilated (or inert) tracer (Roditi and Fisher, 1999). In most cases, gammaemitting radiotracer methods have been used to determine AE values. Using this technique, Roditi and Fisher (1999) found a Cd AE value in the 19-72\% range for the freshwater mussel 
Dreissena polymorpha fed with 8 food types. Recently, the use of stable isotopes instead of radiotracers has been proposed as an improved alternative (Croteau and Luoma, 2005; Croteau et al., 2007). The use of stable instead of radioactive isotopes minimizes the handling and disposal hazards along with the costs, and it increases the range of metals that could be investigated. The AE value of copper could not be measured using radiotracers because the ${ }^{64} \mathrm{Cu}$ half-life (12.7 hours) is too short to perform the pulse-chase experiment. Using the stable isotope tracer ${ }^{65} \mathrm{Cu}$, Croteau and Luoma (2005) have found a $38 \% \mathrm{Cu} \mathrm{AE}$ value for the freshwater clam Corbicula fluminea and Cain et al. (2011) have found that the $\mathrm{Cu} A E$ value was higher than $83 \%$ for various species of mayflies feeding with periphyton.

Although the stable isotope pulse-chase methodology has recently been improved with the use of ${ }^{53} \mathrm{Cr}$ as an unassimilated tracer (Croteau et al., 2007), the application of this promising approach is not straightforward because of the following two issues: (1) the proper labeling of the food that should not alter the natural metal speciation and (2) the discrimination of minute amounts of added tracer from background levels. The precise quantitative determination of a few nanograms of added isotopes remains problematic. Very recently, after the present study was performed, Croteau et al. (2013) have proposed a novel approach of the pulse-chase feeding based on the labeling of the test organisms to circumvent the shortcomings of the method based on food labeling (Croteau et al., 2007) used in this study.

Because of the significance of gammarids in freshwater metal biomonitoring, knowledge of the $\mathrm{Cd}$ and $\mathrm{Cu}$ AE values in G. pulex is important. Therefore, the goal of the present study was to determine the $\mathrm{AE}$ values of $\mathrm{Cd}$ and $\mathrm{Cu}$ in G. pulex, thus enabling the use of a complete biodynamic model for this species. Waterborne uptake parameters have been previously determined (Pellet et al., 2009; Lebrun et al., 2012). Here, the pulse-chase feeding techniques 
110 were associated with the use of stable isotopes to estimate the relative importance of diet-

111 borne exposure.

\section{2 - Materials and methods}

\subsection{Study organisms and materials}

Approximately 100 G. pulex specimens were collected from the Mauldre River at Mareil-sur-

Mauldre (Coordinates RGF93 longitude: 01'52'11" E, latitude: 48 53'42" N) on February 19, 2008. The mean size of the selected gammarids was $12 \pm 2 \mathrm{~mm}(\mathrm{n}=70)$. The animals were maintained in a temperature-controlled incubator $\left(12.1 \pm 0.8^{\circ} \mathrm{C}\right)$ under a 8:16 light:dark cycle

119 (for acclimatization and the experiment). The gammarids were given alder leaves (Alnus glutinosa) ad libitum for $3 \mathrm{~d}$ and starved for the consecutive $3 \mathrm{~d}$ prior to exposure to labeled food. Filtered water (sieved through a $200 \mu \mathrm{m}$ mesh size) from the sampling site was used as the first input in the acclimatization aquaria. This water was progressively renewed by commercial groundwater (Source St Hélène, SE Des Sources Roxane, La Ferrière Bochard,

124 France, $\mathrm{Cd}, \mathrm{Cr}$ and $\mathrm{Cu}$ concentrations were $0.0015,0.028$ and $0.025 \mu \mathrm{g} / \mathrm{L}$, respectively) over

$1256 \mathrm{~d}$. During the experiment, the physical and chemical characteristics of the water were

126 measured (see the supplemental information). The $\mathrm{Cd}$ and $\mathrm{Cu}$ concentrations in gammarids

127 prior to exposure were 0.032 and $74.4 \mathrm{mg} / \mathrm{kg}$, respectively. We purchased $10 \mathrm{mg}$ oxides of

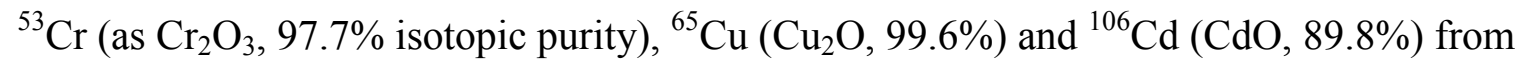

129 Eurisotop (St Aubin, France). The metallic oxides were partially solubilized for at least $7 \mathrm{~d}$ at 130 room temperature in $\mathrm{HNO}_{3}\left(65 \%\right.$ Suprapur, Merck, Darmstadt, Germany) (except for $\mathrm{Cr}_{2} \mathrm{O}_{3}$

131 for which a stronger acidic solubilization procedure was applied using HF (40\% ultrapure,

132 Merck) and heat) and then $1.5 \mathrm{~mL}$ of the supernatant was diluted in $10 \mathrm{~mL}$ ultrapure water, 
133 providing three $100 \mathrm{mg} \mathrm{L}{ }^{-1}$ stock solutions of ${ }^{106} \mathrm{Cd},{ }^{65} \mathrm{Cu}$ and ${ }^{53} \mathrm{Cr}$. A $1,000-\mu \mathrm{g} \mathrm{L}^{-1} \mathrm{Ge}$

134 solution in $0.5 \mathrm{~N} \mathrm{HNO}_{3}$ was prepared by diluting a $1,000 \mathrm{mg} \mathrm{L}^{-1}$ Ge standard solution

135 (PlasmaCal, SCP Science, Courtaboeuf, France).

\subsection{Labeling of the leaf-discs}

137 Alder leaves (A. glutinosa) were collected in November 2007 after abscission and before leaf

138 fall and stored in plastic boxes. The labeling protocol was based on the recommendations

139 from Felten (2003) to favor gammarids appetence for the labeled leaves. Prior to the pulse-

140 chase experiment, the alder leaves were placed in an aquarium filled with several liters of

141 stream water for $20 \mathrm{~d}$ at $12^{\circ} \mathrm{C}$. The water was renewed once (after $2 \mathrm{~d}$ ) to remove the first

142 exudates from the leaves. Twenty leaf-discs were produced using a $2 \mathrm{~cm}$ diameter punch. The

143 discs were exposed for $3 \mathrm{~d}$ to mineral water spiked with ${ }^{53} \mathrm{Cr}\left(413 \mu \mathrm{g} \mathrm{L}^{-1}\right),{ }^{65} \mathrm{Cu}\left(390 \mu \mathrm{g} \mathrm{L}^{-1}\right)$

144 and ${ }^{106} \mathrm{Cd}\left(793 \mu \mathrm{g} \mathrm{L}{ }^{-1}\right)$. These solutions were obtained by diluting $200 \mu \mathrm{L}$ of the ${ }^{53} \mathrm{Cr}$ stock

145 solution, $200 \mu \mathrm{L}$ of the ${ }^{65} \mathrm{Cu}$ stock solution and $400 \mu \mathrm{L}$ of the ${ }^{106} \mathrm{Cd}$ stock solution in $50 \mathrm{~mL}$

146 ultrapure water. Because this medium would be too acidic to allow leaf conservation, drops of

147 a $1 \mathrm{M} \mathrm{NaOH}$ solution (prepared using $\mathrm{NaOH}$ pellets (Acros Organics, SLR pellets extrapure)

148 and deionized water) were added to raise the $\mathrm{pH}$ to 7.5 one minute after introduction of the

149 discs. The rapid rise in $\mathrm{pH}$ favors the binding of the metallic cations to the ligands on the leaf

150 surface, hence adsorbing the metal onto the disc surfaces. After exposure, the discs were

151 rinsed for $4 \mathrm{~d}$ in a $20 \mathrm{~L}$ stirred aquarium with ultrapure (Ultra Analytic M2, Elga, Veolia

152 Water, France) water to remove the weakly adsorbed metals.

\section{$153 \quad$ 2.3. Pulse-chase feeding method}

154 We performed a pulse-chase feeding experiment adapted from previous studies (Croteau et

155 al., 2007). The gammarids were given leaf-discs enriched with stable isotopes during a hot- 
156 feeding phase (the "pulse" phase) of $7 \mathrm{~h}$ and $24 \mathrm{~min}$ and were then were given unlabeled

157 leaf-discs during a 7-d depuration phase. The pulse duration must be shorter than the gut time

158 passage (time to defecate the first tracers after the pulse) to avoid any tracer recycling. Based

159 on previous studies (Smokorowski et al., 1998, Felten, 2003), the G. pulex gut retention time

160 (GRT), i.e., the time to defecate $90 \%$ of the organic matter ingested during the pulse, was

161 assumed to be $3 \mathrm{~d}$. Hence, the gut time passage was expected to be $16 \mathrm{~h}$, applying a 4.5 ratio

162 between the gut time passage and the GRT, as determined by Croteau et al. (2007) for the

163 gasteropod L. stagnalis. The duration of the defecation phase was chosen to ensure complete

164 recovery of the tracers. Moreover, $\mathrm{Cr}$ was assumed to be an inert tracer of the digestion

165 process in gammarids because it is fully unassimilated, allowing the quantification of the

166 ingested tracers at any time during the pulse-chase experiment.

167 Ten feeding chambers allowing the collection of amphipod feces were designed based on

168 Werner's model (Werner, 2000) (photos are provided in the supplemental information). The

169 fecal production of an individual G. pulex within a few hours weighting $\sim 10 \mu \mathrm{g}$, its metal

170 content was not measurable. Therefore, a group of seven G. pulex was used in each chamber.

171 They were placed in the upper portion of a $125 \mathrm{~mm}^{3}$ chamber constructed of $5 \mathrm{~mm}$ mesh

172 cubic bags (immersed) and feces were collected on the bottom of the $600 \mathrm{~mL}$ plastic beakers.

173 In two control treatments, labeled $\mathrm{C} 1$ and $\mathrm{C} 2$ (the eight other treatments were numbered from

1741 to 8 ), unlabeled leaf-discs were given to the gammarids during the pulse. Both the labeled

175 and unlabeled leaf-discs were consumed at the same rate ( $\sim$ one disc per $\mathrm{d}$ by seven

176 gammarids, based on visual observations of food residues). At best, to prevent cannibalism,

177 refuges consisting of a $5 \mathrm{~mm}$ mesh square $\left(6 \mathrm{~cm}^{2}\right)$ wedged into a $5 \mathrm{~L}$ bottle cap were also

178 immersed in each beaker. In one beaker, one gammarid was consumed by its congeners

179 during the pulse. No other mortality was observed over the course of the experiment. 
180 Exuviated molts were re-ingested by the gammarids (no exuviates were observed during the

181 pulse). Approximately five juveniles, newly born during the experiment, were removed from

182 the beakers when discovered. Feces were harvested at 8.5, 24, 36, 48, 72, 96 and $166 \mathrm{~h}$

183 according to the following method. The feces were concentrated in a clean $5 \mathrm{~cm}$ diameter

184 plastic Petri dish using a $10 \mathrm{~mL}$ polyethylene pipette. This concentrate was transferred to the

185 top of a filtering system (a polytetrafluoroethylene (PTFE) filter unit on a vacuum system)

186 and filtered through a PTFE membrane filter (Whatman, $0.45 \mu \mathrm{m}$ pore size, $25 \mathrm{~mm}$ ). At the

187 end of the experiment, the gammarids were dried for metal analysis. Filtered water samples

188 (Whatman PTFE, $10 \mathrm{~mL}$ syringe filters, $0.5 \mu \mathrm{m}$ ) were obtained from each replicate at the

189 beginning of the pulse and before every feces collection. The samples were immediately

190 acidified by the addition of $200 \mu \mathrm{L}$ ultrapure nitric acid. The leaves remaining at the end of

191 the pulse were also collected for metal analysis.

\section{2.4. Preparation of the samples}

193 The feces on the filters, the reference material ERM-CE 278 mussel tissue (IRMM, Brussels,

194 Belgium) and the pools of gammarids were dried for $48 \mathrm{~h}$ at $45^{\circ} \mathrm{C}$ and handled in individual

195 covered Petri dishes to prevent atmospheric deposition of trace metals. The fecal matter was

196 weighed on pre-weighted PTFE filters on a microbalance (Sartorius SE 2-F, $0.1 \mu \mathrm{g}$ ). Ultra-

197 clean or disposable material was used throughout. The vessels, beakers and the PTFE filtering

198 system were acid washed in a $10 \% \mathrm{HNO}_{3}$ bath for $48 \mathrm{~h}$ and rinsed with ultrapure water before

199 use. The mussel tissue reference material (ERM-CE278, 40 and $132 \mathrm{mg}$ ) and the gammarids

200 (a pool of seven gammarids of approximately $40 \mathrm{mg}$ ), leaves $(\approx 10 \mathrm{mg}$ ) and feces (pooled

201 feces of the experimental group of gammarids $\approx 4 \mathrm{mg})$ were digested with $\mathrm{HNO}_{3}(65 \%$

202 Suprapur, Merck, Darmstadt, Germany) (50 $\mu \mathrm{L}$ per $\mathrm{mg}$ ) for $24 \mathrm{~h}$ followed by the addition of

$20320 \mu \mathrm{L} \mathrm{mg}^{-1} \mathrm{H}_{2} \mathrm{O}_{2}\left(30 \%\right.$ (w/w) in $\mathrm{H}_{2} \mathrm{O}$, Sigma-Aldrich) in closed SCP-Science polyethylene 
204 tubes for DigiPrep. Subsequently, the solution was heated to $95^{\circ} \mathrm{C}$ for approximately $4 \mathrm{~h}$ in 205 a DigiPrep Block (SCP Science) under a laminar flow hood to ensure evaporation to near 206 dryness. The samples were immediately removed from the heating block when dryness was 207 reached $\left(100 \mu \mathrm{L}\right.$ residue maximum) and volume adjusted to $5 \mathrm{~mL}$ with a $0.5 \mathrm{~N} \mathrm{HNO}_{3}$

208 solution. Finally, $5 \mu \mathrm{L}$ of a $1,000 \mu \mathrm{g} \mathrm{L}^{-1}$ Ge solution was added to the sample solutions 209 because Ge was used in this study as an internal standard to monitor the ICP-MS signal drifts 210 (see below). All of the volumes were monitored by weighing the tubes at relevant steps during 211 preparation of the samples.

\subsection{ICP-(CCT)-MS analysis}

213 Chromium isotopes (of atomic mass 50, 52, 53 and 54), copper (of atomic mass 63 and 65), 214 cadmium (of atomic mass 106, 108, 110, 111, 112, 113, 114 and 116) and germanium (of 215 atomic mass 72 and 74) were analyzed by an ICP-MS equipped with collision-cell technology 216 (CCT) (CCT-X Series, ThermoFisher Scientific, Courtaboeuf, France), as proposed by Nixon 217 et al. (2000) for interference-free measurements of $\mathrm{Cr}$ isotopes. The isobaric interferences on 218 the determination of $\mathrm{Cr}$ isotope concentrations have been identified by Croteau et al. (2007) 219 as one of the primary analytical issues of the method. The samples were analyzed in the 220 standard mode and in the CCT mode with no mathematical corrections for interferences and 221 Ge was used as an internal standard.

222 Quality controls of the ICP-MS calibration consisted of analysis of SRM 1640 river water 223 sample (NIST, Gaithersburg, Maryland USA) and mussel tissue ERM-CE 278 in duplicates. 224 In the CCT mode, the limits of detection (LOD), defined as the mean of ten blank signals plus 225 three times the standard deviation (SD) of the blank, were as follows: $0.001 \mu \mathrm{g} \mathrm{L}^{-1}$ for ${ }^{53} \mathrm{Cr}$, 226 $0.0025 \mu \mathrm{g} \mathrm{L}{ }^{-1}$ for ${ }^{65} \mathrm{Cu}$ and $0.0002 \mu \mathrm{g} \mathrm{L}{ }^{-1}$ for ${ }^{106} \mathrm{Cd}$. 
227 The net tracer concentrations were determined using the equations adapted from Croteau et 228 al. (2004) (see Supporting Information).

\subsection{Ingestion rate and assimilation efficiencies calculation}

230 To calculate the net amounts of the ingested tracers, the mass of the leaf-discs ( $m_{\text {leaves }}$ in $\left.\mathrm{mg}\right)$

231 ingested by a pool of gammarids during the pulse was determined as the cumulative net 232 amount of ${ }^{53} \mathrm{Cr}$ defecated during the depuration, $\Sigma^{53} \mathrm{Cr}_{\text {feces }}(\mathrm{ng})$ divided by the net ${ }^{53} \mathrm{Cr}$ 233 concentration $\left(\mathrm{ng} \mathrm{mg}^{-1}\right)$ in the remaining parts of the leaf-discs sampled at the end of the 234 pulse, as described in the following equation:

$$
m_{\text {leaves }}=\frac{\sum^{53} C r_{\text {feces }}}{\left[{ }^{53} \mathrm{Cr}\right]_{\text {leaves }}} \quad \text { Equation } 1
$$

236 The net tracer amounts of the ingested ${ }^{106} \mathrm{Cd}$ and ${ }^{65} \mathrm{Cu}\left({ }^{106} \mathrm{Cd}_{\text {leaves }}\right.$ and $\left.{ }^{65} \mathrm{Cu}_{\text {leaves }}\right)$ were

237 calculated by multiplying $m_{\text {leaves }}$ by the net tracer concentrations of ${ }^{106} \mathrm{Cd}$ and ${ }^{65} \mathrm{Cu}$ in the 238 leaves.

239 The mean ingestion rate IR $\left(\mathrm{g} \mathrm{g}^{-1} \mathrm{~d}^{-1}\right)$ was calculated as the $m_{\text {leaves }}$ divided by the dry mass of 240 the gammarids $\left(m_{\text {org }}\right)$ at the end of the experiment and the duration of the pulse.

241 The assimilation efficiency (the fraction of ingested metal that remains in the organism) was

242 calculated using the following two methods: the mass balance method (Luoma and al., 1992;

243 Cain et al., 2011) and the ratio method (Wang and Fisher, 1999).

244 Using the mass balance method, the $\mathrm{AE}$ values for $\mathrm{Cu}$ and $\mathrm{Cd}$ were calculated under the 245 assumption that the net amount of ingested metal is equal to the sum of the defecated and 246 internalized tracers. Note that this calculation does not consider the mass of the ingested food 247 or its contamination. For example, for $\mathrm{Cd}$, the $\mathrm{AE}$ value was calculated as follows: 
$248 \quad A E=\frac{\Delta^{106} C d_{\text {org }}}{\Delta^{106} C d_{\text {org }}+\sum^{106} C d_{\text {feces }}} \quad$ Equation 2

249 Using the ratio method, the AE value is derived directly from the ICP-MS signals of the

250 isotopes, including the ${ }^{53} \mathrm{Cr}$ tracer, e.g., for $\mathrm{Cd}$, see the following Eq. 3:

$251 \quad A E=1-\frac{\left({ }^{106} \mathrm{Cd} /{ }^{53} \mathrm{Cr}\right)_{\text {feces }}}{\left({ }^{106} \mathrm{Cd} /{ }^{53} \mathrm{Cr}\right)_{\text {leaves }}} \quad$ Equation 3

252 where $\left({ }^{106} \mathrm{Cd} /{ }^{53} \mathrm{Cr}\right)_{\text {feces }}$ is the ratio of the ${ }^{106} \mathrm{Cd}$ and ${ }^{53} \mathrm{Cr}$ signal intensities in the feces after

253 depuration and $\left({ }^{106} \mathrm{Cd} /{ }^{53} \mathrm{Cr}\right)_{\text {leaves }}$ is the ratio of the ${ }^{106} \mathrm{Cd}$ and ${ }^{53} \mathrm{Cr}$ signal intensities in the

254 spiked leaf-discs. Using the ratio method, ${ }^{106} \mathrm{Cd}$ org is assumed equal to the difference between

$255{ }^{106} \mathrm{Cd}_{\text {leaves }}$ and $\Sigma^{106} \mathrm{Cd}_{\text {feces }}$ and the mass of the ingested tracer is evaluated through the inert

256 tracer ${ }^{53} \mathrm{Cr}$. The primary advantage of the ratio method over the mass balance method is that

257 the AE value can be calculated even if the defecation is incomplete. Additional

258 methodological considerations on the ratio method have been provided elsewhere (Wang and

259 Fisher, 1999; Croteau et al., 2007). In this study, only the first sample of collected feces was

260 considered. In subsequently produced feces, the ${ }^{53} \mathrm{Cr}$ signal intensities were less than two

261 times that of the control feces, validating the application of the ratio method to the first feces

262 defecated, under the hypothesis that all of the tracers at stake are released simultaneously

263 (Wang and Fisher, 1999). This point was further tested by studying the tracer defecation

264 profiles. 


\section{3. Results and discussion}

\section{3.1. ICP-(CCT)-MS analytical performances}

268 The observed concentrations of $\mathrm{Cd}$ and $\mathrm{Cu}$ were within $7 \%$ of the reference values in the $\mathrm{CCT}$ 269 and standard modes (ERM-CE 278 mussel tissue (Fig. 1) and SRM-1640 water). In opposite, 270 the $\mathrm{Cr}$ determined concentrations were significantly different from the certified values for the

271 certified mussel tissue (Fig. 1). Because the reference material is not tracer-enriched, the

272 concentration of one element should be the same regardless of the isotope used to calculate it; 273 this was confirmed for the CCT mode only. Nevertheless, the observed Cr concentrations in 274 the CRM mussel tissue were lower than the certified value with a $36 \%$ underestimation. The 275 underestimation value was constant from a replicate, from one isotope to another and when 276 increasing the mass of the digested mussel tissue. The digestion procedure used for

277 certification being potentially more effective for Cr compounds solubilization (Lamberty and 278 Muntau, 2005) than that the one we applied, we attributed the $36 \%$ underestimation value on 279 the $\mathrm{Cr}$ isotope concentrations observed to a partial but reproducible digestion and assumed an 280 identical underestimation for all of the solid samples (tissue, feces and leaves).

281 The CCT mode, by decreasing the polyatomic interferences, primarily with argide ions

$282\left({ }^{12} \mathrm{C}^{40} \mathrm{Ar}\right)$ on ${ }^{52} \mathrm{Cr}$ and $\left({ }^{37} \mathrm{Cl}^{16} \mathrm{O}\right)$ and $\left({ }^{13} \mathrm{C}^{40} \mathrm{Ar}\right.$ ) (Tanner et al., 2002), significantly improved the 283 isotope content determination in digested invertebrates, feces and leaves, as previously 284 observed by Hammer et al. (2005) for $\mathrm{Cr}$ analysis in foodstuffs. 
- CCT mode $\quad \circ$ standard mode

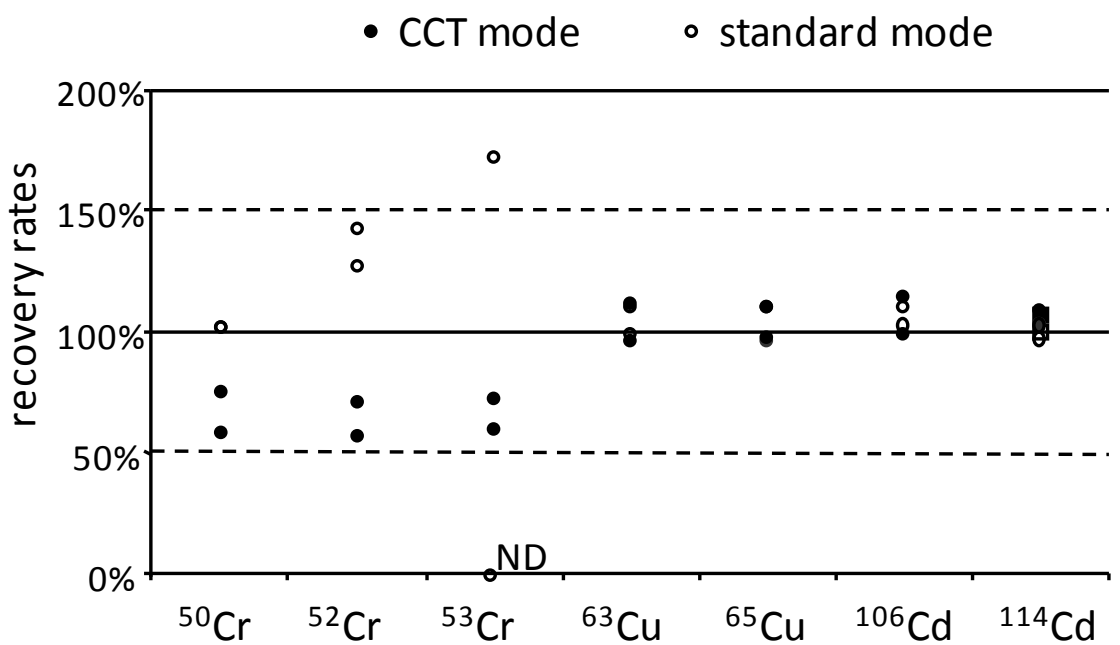

Figure 1: The use of collision cell technology (CCT) improves the $\mathrm{Cr}$ analysis regularity among its various isotopes. The recovery rates of $\mathrm{Cr}, \mathrm{Cu}$ and $\mathrm{Cd}$ in the reference material mussel tissue (ERM-CE-278) were inferred from various isotopes of $\mathrm{Cr}, \mathrm{Cu}$ and $\mathrm{Cd}$ and are expressed as a percentage of the certified value. The empty marks represent the results in the standard mode, and the filled marks are those in the CCT mode. ND represents "not determined" (the ${ }^{53} \mathrm{Cr}$-signal in the standard mode for one sample was inferior to the blank value).

Consequently, the subsequent results were based on the ICP-(CCT)-MS. We verified that the results derived from the net ${ }^{53} \mathrm{Cr}$ measurement (the mass of ingested leaves, IR and AE calculations) remained unchanged regardless of whether we corrected the $\mathrm{Cr}$ concentrations of the $36 \%$ underestimation.

\subsection{Tracer analysis in samples of various matrices}

The stable isotope concentrations in the labeled alder leaf-discs are presented in Fig. 2. The

300 ratios of the tracer concentration in labeled food to that in unlabeled food were 119 for $\left({ }^{53} \mathrm{Cr}\right)$,

3014.7 for $\left({ }^{65} \mathrm{Cu}\right)$ and 2914 for $\left({ }^{106} \mathrm{Cd}\right)$. The $\mathrm{Cu}$ enrichment of the leaves was less than that of

302 other tracers, which is a consequence of the high natural content of copper in alder leaves

303 compared with $\mathrm{Cr}$ and $\mathrm{Cd}$ and of the high natural abundance of ${ }^{65} \mathrm{Cu}$. As a result, the total metal concentration in labeled leaves was significantly increased compared to the unlabeled 
ones, but did not exceed the metal concentration in litter sampled in a river draining an ancient uranium mining site (Schaller et al., 2010).

Labeled leaves

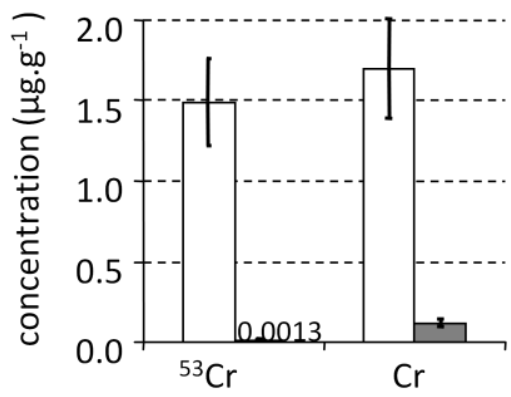

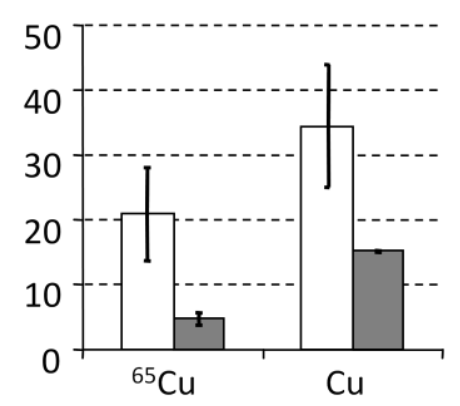

Unlabeled leaves

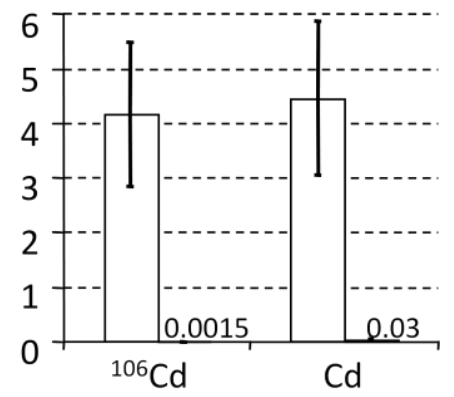
the net ${ }^{53} \mathrm{Cr}$ amount recovered during the experiment. Afterwards, a sharp decrease in the

Figure 2: Tracer and elemental composition of the alder leaf-discs. White bars: discs labeled with the three tracers, mean value $(n=7)$. Gray bars: unlabeled discs. Mean value \pm SD $(n=10)$.

The concentrations of the tracers initially occurring in the water a few minutes after introduction of gammarids and leaves were as follows: $\left[{ }^{53} \mathrm{Cr}\right]<\mathrm{LOD},\left[{ }^{65} \mathrm{Cu}\right]=275 \pm 123 \mathrm{ng}$ $\mathrm{L}^{-1},\left[{ }^{106} \mathrm{Cd}\right]=2.2 \pm 0.7 \mathrm{ng} \mathrm{L}-1(\mathrm{n}=8)$. At the end of the pulse period, the ${ }^{53} \mathrm{Cr}$ concentration remained undetectable, the ${ }^{65} \mathrm{Cu}$ concentration remained stable $\left(\left[{ }^{65} \mathrm{Cu}\right]=352 \pm 114 \mathrm{ng} \mathrm{L}{ }^{-1}\right.$, $(\mathrm{n}=8)$ and the ${ }^{106} \mathrm{Cd}$ concentration increased significantly to $11 \pm 4 \mathrm{ng} \mathrm{L}^{-1}(\mathrm{n}=8)$ (Student $t$ test, $p=6.10^{-6}$ ). During the depuration, the concentrations of the tracers in the water were below the detection limits, except for ${ }^{65} \mathrm{Cu}\left(\left[{ }^{65} \mathrm{Cu}\right]=167 \pm 41 \mathrm{ng} \mathrm{L}^{-1}\right)$.

The three tracers were nearly completely defecated by the gammarids $(>95 \%)$ within the first three time steps (Fig. 3), and the initial feces (collected at $8.5 \mathrm{~h}$ ) contained as much as $82 \%$ of fecal tracer content was observed within the first two days. The gut retention time was $24 \mathrm{~h}$, 
324 which is three times less than what was expected based on previous studies (Smokorowski 325 et al., 1998; Felten, 2003). This value is similar to that in the snail Lymnaea stagnalis (22.5 h

326 (Croteau et al., 2007)). The high contribution of the first sample of feces to the overall fecal contamination suggests that gammarids began to excrete tracers before $9 \mathrm{~h}$. Thus, the gut time passage could not be precisely determined by the present study; however, it was clearly less 329 than $9 \mathrm{~h}$.

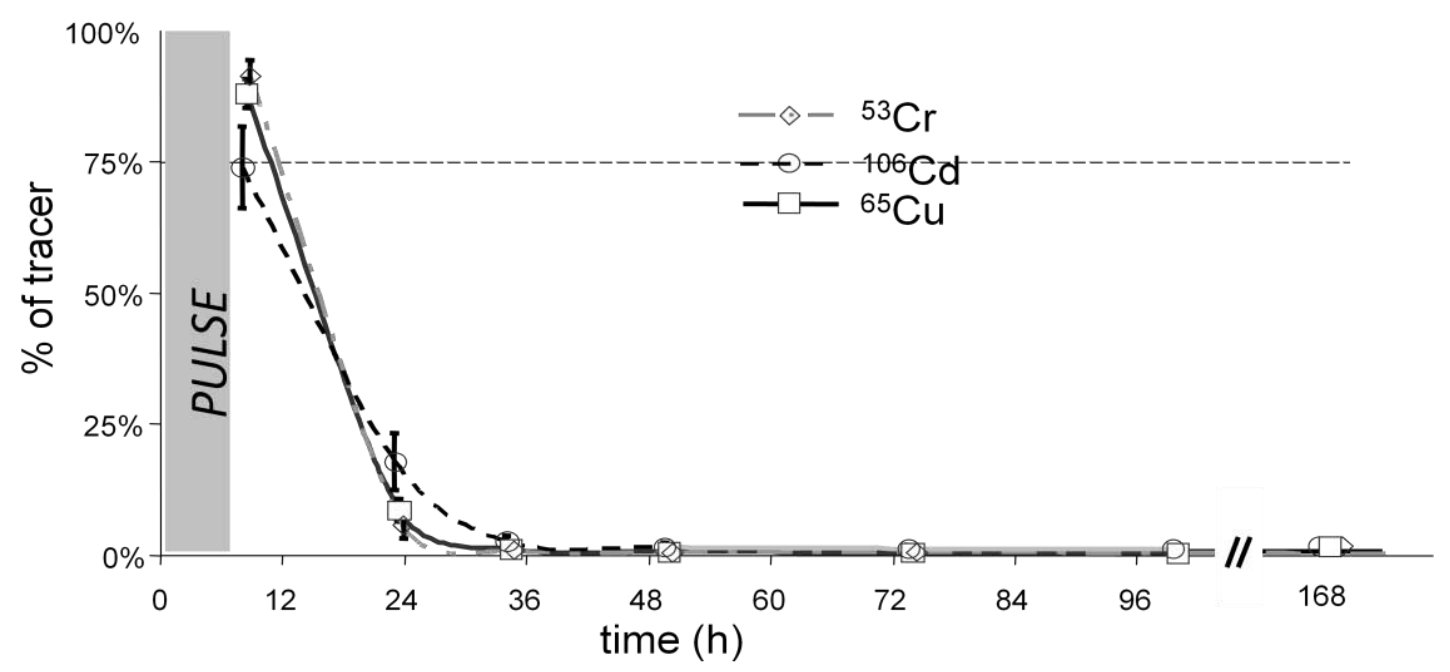

Figure 3: Time series of the fecal tracer release (\%). Mean \pm SD $(n=8)$ of the normalized fecal release (by the sum of the defecated tracer amounts) for each tracer during the 333 depuration phase.

335 Gammarids did not accumulate detectable amounts of ${ }^{53} \mathrm{Cr}$. It was verified a posteriori that ${ }^{53} \mathrm{Cr}$ was not absorbed through the diet and could be used as the inert tracer for digestion in 337 gammarids. The cumulative amounts of chromium recovered in the feces and the net tracer 338 concentrations in the labeled leaves led to a mean IR of $0.69 \pm 0.21 \mathrm{~g} \mathrm{~g}^{-1} \mathrm{~d}^{-1}$. During the pulse 339 (7 h $24 \mathrm{~min}$ ), the G. pulex consumed the quantity of food typically consumed in one or two 340 days (see Maltby et al. (2002) for the reference ingestion rate), most likely because of the $3 \mathrm{~d}$ 341 starvation period that preceded the experiment. The high IR value also validates the leaves 
342 labeling protocol, as Malty et al. (2002) showed that gammarids may decrease their feeding

343 rate in polluted environments.

344 On average, two molts were re-ingested by each group of gammarids during the depuration

345 phase. The mass of an exuviate was approximately $2.5 \mathrm{mg}$, representing less than $10 \%$ of the

346 mass of the food ingested during the depuration phase. Thus, molt ingestion was not

347 considered in further calculations and should not represent a bias of the pulse-chase feeding

348 method.

$349{ }^{65} \mathrm{Cu}$ and ${ }^{106} \mathrm{Cd}$ were internalized in the gammarids after the $7-\mathrm{d}$ experiment at net tracer 350 concentrations of $378 \pm 102$ and $161 \pm 81 \mathrm{ng} \mathrm{g}^{-1}(\mathrm{n}=8)$ respectively (vs. 100 and $6 \mathrm{ng} \mathrm{g}^{-1}$, 351 respectively, in the control treatments, $\mathrm{n}=2$ ).

352 To estimate the amount of the assimilated tracer in the gammarids during the pulse, the 353 measurement of the tracers in the gammarids at the end of the depuration phase should be 354 corrected from the possible waterborne influx during the pulse and from the efflux that 355 occurred during the depuration phase. Because of the $\mathrm{Cd}$ tracer leakage during the pulse, 356 approximately $0.06 \mathrm{ng}$ of ${ }^{106} \mathrm{Cd}$ may have been taken up by the gammarids by water uptake 357 (considering a $9 \mathrm{ng} \mathrm{L}^{-1}$ tracer concentration in the water, an uptake rate from the water of 0.46 $358 \mathrm{~L} \mathrm{~g}^{-1} \mathrm{~d}^{-1}$ (Pellet et al., 2009), a $40 \mathrm{mg}$ dry weight of gammarids and a $0.31 \mathrm{~d}$ pulse duration).

359 This value was fifty times lower than the animal body burden at the end of the depuration

360 phase (Table 1). Thus, the contribution of water to the overall tracer accumulation was

361 neglected. Given the $0.032 \mathrm{~d}^{-1}$ efflux rate, $19 \%$ of $\mathrm{Cd}$ assimilated during the pulse should have

362 been excreted during the depuration phase. Thus, to estimate the Cd body burden at the end of 363 the pulse, a $19 \%$ correction was applied to the amount of ${ }^{106} \mathrm{Cd}$ measured in the gammarids 364 for the Cd AE calculations. 
367 Table 1. Net ${ }^{106} \mathrm{Cd}$ amounts (ng) in the various matrices and the mass balance of the net ${ }^{106} \mathrm{Cd}$ assimilation efficiency of $\mathrm{Cd}$. The amount of ingested tracer was estimated from the amount of ${ }^{53} \mathrm{Cr}$ measured in the feces. The tracer content of the gammarids at the end of the pulse was estimated from the amount measured at the end of the experiment, the efflux rate of Cd (Pellet et al., 2009) and the depuration time. The mass balances were evaluated as the ratio of ${ }^{106} \mathrm{Cd}$ outputs (for the gammarids at the end of the pulse and the feces) and inputs (the leaves). The assimilation efficiency was estimated from the mass balance and the ratio methods (see text).

\begin{tabular}{|c|c|c|c|c|c|c|c|c|}
\hline & \multirow{2}{*}{$\begin{array}{l}\text { Ingested } \\
\text { Leaves }\end{array}$} & \multirow{2}{*}{$\begin{array}{c}\text { Leakage } \\
\text { during } \\
\text { pulse }\end{array}$} & \multirow[t]{2}{*}{ Feces } & \multicolumn{2}{|c|}{ Gammarids } & \multirow{2}{*}{$\begin{array}{c}\text { Mass } \\
\text { balance }\end{array}$} & \multicolumn{2}{|c|}{ Assimilation efficiency } \\
\hline & & & & $\begin{array}{l}\text { end of } \\
\text { exp. }\end{array}$ & $\begin{array}{l}\text { after the } \\
\text { pulse }\end{array}$ & & $\begin{array}{c}\text { mass balance } \\
\text { method }\end{array}$ & ratio method \\
\hline & 108 & 5 & 68 & 5.4 & 6.7 & $70 \%$ & $9 \%$ & $16 \%$ \\
\hline 2 & 87 & 3 & 51 & 5.1 & 6.3 & $66 \%$ & $11 \%$ & $19 \%$ \\
\hline 3 & 54 & 3 & 50 & 4.0 & 4.9 & $101 \%$ & $9 \%$ & $29 \%$ \\
\hline 4 & 129 & 7 & 31 & 9.2 & 11.4 & $33 \%$ & $27 \%$ & $47 \%$ \\
\hline 5 & 93 & 5 & 66 & 5.4 & 6.6 & $78 \%$ & $9 \%$ & $18 \%$ \\
\hline 6 & 49 & 3 & 28 & 3.0 & 3.8 & $65 \%$ & $12 \%$ & $42 \%$ \\
\hline 7 & 161 & 8 & 111 & 13.8 & 17.1 & $80 \%$ & $13 \%$ & $5 \%$ \\
\hline 8 & 128 & 6 & 71 & 6.7 & 8.2 & $62 \%$ & $10 \%$ & $12 \%$ \\
\hline $\begin{array}{l}\text { Mean } \\
(\mathrm{n}=8)\end{array}$ & 101 & 5 & 60 & 6.6 & 8.1 & $69 \%$ & $13 \%$ & $24 \%$ \\
\hline $\mathrm{SD}$ & 38.2 & 1.9 & 26.3 & 3.4 & 4.3 & $19 \%$ & $6 \%$ & $15 \%$ \\
\hline
\end{tabular}

376 Similarly, gammarids exposed to $352 \mathrm{ng} \mathrm{L}{ }^{-1}$ of dissolved ${ }^{65} \mathrm{Cu}$ should have taken up $61 \mathrm{ng}$ of

${ }^{65} \mathrm{Cu}$ from waterborne exposure (given a $16.9 \mathrm{~L} \mathrm{~g}^{-1} \mathrm{~d}^{-1}$ influx rate and a $1.2 \mathrm{~d}^{-1}$ efflux rate

378 (Lebrun et al., 2012)). In contrast to Cd, this value is in the same range as the amount

379 remaining in the gammarids at the end of the depuration phase $(33 \pm 4 \mathrm{ng}$ in the pool of 69

380 gammarids). Given the efflux rates of $\mathrm{Cu}$, more than $99 \%$ of the assimilated $\mathrm{Cu}$ should have

381 been excreted during the depuration phase (the calculated ${ }^{65} \mathrm{Cu}$ internalized immediately after

382 the pulse is $42500 \pm 11615 \mathrm{ng}$ ). Therefore, the waterborne exposure via potential feces

383 dissolution is not negligible in the amount of assimilated metal during the pulse, but the latter 
cannot be determined properly. In our study, the rapid exchange rates of $\mathrm{Cu}$ in the gammarids prevent the evaluation of the assimilation of diet-borne copper with the pulsechase feeding method. The half-time of the substance must be significantly larger than the GRT, which is the case for Lymnaea (Croteau et al., 2007) or mayflies (Cain et al., 2011) but clearly not for gammarids.

\subsection{Derivation of the assimilation efficiencies}

\subsubsection{The case of copper}

The entire duration of the experiment was too short in regards to copper regulation, preventing the application of the mass balance method; however, the ratio method, limited to the first collected feces sample, still applies. The tracer ratio in the leaves was constant during the experiment, and one can assume than the tracer ratio in the feces is not biased by possible waterborne exposure or tracer released in the water. However, the copper AE value could not be determined by the ratio method because the ${ }^{65} \mathrm{Cu} /{ }^{53} \mathrm{Cr}$ ratios of the leaf-discs $(26 \pm 5.7$, $n=7)$ were lower than those in the feces $(37 \pm 6.5, n=7)$, which hinders the determination of the $\mathrm{Cu} A E$ value by this method. The unexpected enhancement of the ${ }^{65} \mathrm{Cu} /{ }^{53} \mathrm{Cr}$ ratio in the feces compared with that of the leaves was attributed to an analytical issue in the ${ }^{65} \mathrm{Cu}$ determination. Because neither feces from the control experiment nor the blank values of the filtration method were contaminated in ${ }^{65} \mathrm{Cu}$, it is unlikely that the ratio enhancement is due to ${ }^{65} \mathrm{Cu}$ overestimation in the feces. $\mathrm{A}^{65} \mathrm{Cu}$ underestimation in the leaves occurred, which was most likely due to a matrix effect on the copper measurements in the ICP-(CCT)-MS and/or incomplete digestion. A specific and reinforced digestion procedure for the determination of trace level metallic isotopes in the labeled leaf matrix, following the recommendations of Lamberty and Muntau (2005), could improve the ${ }^{65} \mathrm{Cu}$ determination in the leaves. 
407 Additionally, a collision gas mixture containing ammonia would be more efficient than the $408 \mathrm{H}_{2} / \mathrm{He}$ mixture used in this study to reduce the isobaric interferences due to ${ }^{44} \mathrm{Ca}^{18} \mathrm{OH}^{+}$and

$409{ }^{48} \mathrm{Ca}^{16} \mathrm{OH}^{+}$ions on the ${ }^{63} \mathrm{Cu}$ and ${ }^{65} \mathrm{Cu}$ determinations, respectively, which are interferences 410 that degrade the precision of the isotope content determination (Fialho et al., 2011). Finally, 411 the use of high resolution-ICP-MS may efficiently prevent those analytical issues.

412 Copper AE values are rare in the literature because of the lack of a suitable radiotracer 413 (Croteau et al., 2004). Hence, one important goal of the present study was to test the 414 feasibility of using ${ }^{65} \mathrm{Cu}$ to trace $\mathrm{Cu}$ assimilation in an amphipod. The ability of gammarids to 415 rapidly regulate internalized copper and the relative liability of the element in an organic 416 matrix, which tends to be released in water, added to the analytical issues in the determination 417 of stable isotopes of copper, hindering the determination of the copper AE value for the 418 crustacean G. pulex.

\subsubsection{Cadmium assimilation efficiency}

420 The ratios of ${ }^{106} \mathrm{Cd} /{ }^{53} \mathrm{Cr}$ were significantly higher in the leaves compared with the feces. The 421 corresponding AE values calculated with the ratio method are given in Table 1. The mean 422 cadmium AE value was $24 \% \pm 15 \%(n=8)$. The assimilation efficiencies of cadmium were 423 also evaluated for each replicate with the mass balance method using the amount of tracer 424 measured in the gammarids and in the feces. The results, displayed in Table 1, are lower than 425 the AE values estimated with the ratio method. This discrepancy is at least partly explained by 426 the unbalanced budget of ${ }^{106} \mathrm{Cd}$, as displayed in Table 1 in which the sum of ${ }^{106} \mathrm{Cd}$ in the 427 gammarids and feces is lower than the estimated amount of ingested ${ }^{106} \mathrm{Cd}$. It is possible that a 428 portion of the tracer in the feces is leaked into the water and not measured, which would 429 explain part of the unbalanced budget and the underestimation of the ${ }^{106} \mathrm{Cd} /{ }^{53} \mathrm{Cr}$ ratio and the 
430 net amount of ${ }^{106} \mathrm{Cd}$ in the feces. Consequently, in both methods, the AE value would have

431 been overestimated. However, Cd leakage from the feces is necessarily limited because no

432 significant net amount of ${ }^{53} \mathrm{Cr}$ was measured in the water at the end of the experiment.

433 Despite the variation in the estimated AE value according to the calculation method, we infer

434 that the $\mathrm{Cd} \mathrm{AE}$ value for G. pulex is within the range of 5-47\%. Although associated with a

435 high uncertainty, all of the estimations of the $\mathrm{Cd}$ AE values for G. pulex are lower than those

436 measured for the amphipod Mysis relicta (the AE value is estimated as $72 \%$, and the tracer

437 defecation kinetics in Mysis occur with an approximate GRT of 2 d (Smokorowski et al.,

438 1998)) or to other species, such as gastropods (AE $>73 \%$ in Lymnaea stagnalis, Croteau et al.,

439 2007), bivalves (AE values in the 19-72\% range for Dreissena polymorpha, Roditi and

440 Fisher, 1999) or mayflies (AE $>71 \%$ for all of the tested species (Cain et al., 2011)). Higher

441 assimilation efficiencies of metals are generally associated with longer food processing times

442 (Decho and Luoma, 1996; Croteau and Luoma, 2005). Thus, the AE values in the present

443 study may have been influenced by the rapid food processing in this particular experiment.

444 Gammarids in the field withstand starvation periods of more than $10 \mathrm{~d}$ (Felten, 2003) and can

445 store food in their midgut (Correia and al., 2002); hence, their GTP is plausibly variable.

446 Therefore, the influence of the GTP on the metal AE value in gammarids may deserve further

447 investigation for diet-borne uptake. Indeed, the design of the stable isotopes based pulse-chase

448 feeding method brings a number of potential sources of stresses that may affect strongly the

449 GTP whatever our concerns about favoring appetence and limiting stress factors along the

450 experiment. 


\subsection{Waterborne uptake vs. diet-borne uptake of cadmium}

452 Based on the estimated $\mathrm{Cd}$ assimilation efficiencies, we evaluated the relative contribution of

453 diet-borne exposure in gammarids to Cd contamination. Leaves, gammarids and water

454 samples were obtained in April 2008 in an upper affluent of La Mauldre River at Vicq

455 (Coordinates RGF93 longitude: 0149'57" E, latitude: $48^{\circ} 48^{\prime} 49^{\prime \prime} \mathrm{N}$ ). Three types of leaves

456 located in amphipod habitats were sampled in duplicates as follows: leaves in fine gravel

457 habitats, showing signs of an advance bacterial and fungal decomposition process; the same

458 type of leaves in fine sediments; green leaves, immersed and showing fractionation marks.

459 Pools of five adult gammarids of approximately $10 \mathrm{~mm}$ were sampled at the sampling site

460 (eight replicates). The organisms and soft parts of the leaves were dried, weighted and then

461 digested using a protocol described elsewhere (Pellet et al., 2009). The metal labile

462 concentrations in the water were estimated at the sampling site using the diffusive gradient in

463 thin-films (DGT) technique (Davison and Zhang, 1994) by measuring the labile metal

464 concentration using six thin films. Deployment and data processing are described elsewhere

465 (Tusseau-Vuillemin et al., 2007). Pellet et al. (2009) have previously shown that the

466 waterborne Cd uptake in gammarids could be better estimated based on the labile $\mathrm{Cd}$

467 concentration rather than the total dissolved concentration. The Cd contents of all of the

468 samples were analyzed by graphite furnace atomic absorption spectrometry (GF-AAS Varian

469 SpectrAA-20, Les Ulis, France).

470 The Cd concentration in the gammarids was estimated following the biodynamic model at

471 steady-state, according to the following Eq. 4 (Luoma and al., 1992):

472

$[M]_{\text {org }}^{S S}=\frac{A E \cdot I R}{k_{e}} \cdot[M]_{\text {leaves }}+\frac{k_{u}}{k_{e}}[M]_{w} \quad$ Equation 4 
473 where $[\mathrm{M}]_{\mathrm{org}} \mathrm{SS}$ is the metal concentration in the gammarids at steady state $\left(\mu \mathrm{g} \mathrm{g}^{-1}\right),[\mathrm{M}]_{\text {leaves }}$

474 is the metal concentration in the leaves $\left(\mathrm{ng} \mathrm{g}^{-1}\right), \mathrm{k}_{\mathrm{u}}$ is the waterborne uptake rate $\left(\mathrm{L} \mathrm{g}^{-1} \mathrm{~d}^{-1}\right)$,

475 and $[\mathrm{M}]_{\mathrm{w}}$ is the labile metal concentration in the water $\left(\mathrm{ng} \mathrm{\textrm {L } ^ { - 1 }}\right)$. The parameters and the

476 measured concentrations are reported in Table 2 . The $\mathrm{k}_{\mathrm{u}}$ and $\mathrm{k}_{\mathrm{e}}$ values were obtained from

477 Pellet et al. (2009). A $0.1 \mathrm{~g} \mathrm{~g}^{-1} \mathrm{~d}^{-1}$ value was estimated based on the measurement of the

478 ingestion rate at $14^{\circ} \mathrm{C}$ by Maltby et al. (2002). This selected IR value is significantly lower

479 than the value measured during the pulse-chase experiment that could be artificially increased

480 by the starvation step. This will minimize the estimation of the diet-borne uptake.

Table 2: Biodynamic forecasts of Cd bioaccumulation in G. pulex. $[\mathrm{M}]_{\mathrm{w}}$ is the labile metal concentration measured by the diffusive gradient in thin films technique. [M] $]_{\mathrm{org}}^{\mathrm{SS}}$ is the estimation at steady state of the Cd body burden in G. pulex. The max and min data correspond to the maximal and minimal contaminations of the food and the subsequent results in terms of bioaccumulation modeling.

\begin{tabular}{|c|c|c|c|c|}
\hline $\begin{array}{l}\text { Assimilation efficiency } \\
\text { Ingestion rate } \\
\text { Uptake rate from water } \\
\text { Elimination rate }\end{array}$ & $\begin{array}{l}\mathrm{AE} \\
\mathrm{IR} \\
\mathrm{k}_{\mathrm{u}} \\
\mathrm{k}_{\mathrm{e}}\end{array}$ & $\begin{array}{c}\quad \% \\
\operatorname{g~g}^{-1} d^{-1} \\
\operatorname{L~g~}^{-1} d^{-1} \\
d^{-1}\end{array}$ & & $\begin{array}{c}18 \\
0.1 \\
0.40 \\
0.032\end{array}$ \\
\hline $\begin{array}{c}\text { Field observations } \\
\text { Leaves concentration } \\
\text { Water labile concentration } \\
\text { G. pulex body-burden }\end{array}$ & $\begin{array}{c}{[\mathrm{M}]_{\text {leaves }}} \\
{[\mathrm{M}]_{\mathrm{W}}} \\
{[\mathrm{M}]_{\text {org }}} \\
\end{array}$ & $\begin{array}{l}\mu \mathrm{g} \mathrm{g}^{-1} \\
\mu \mathrm{g} \mathrm{g}^{-1} \\
\mathrm{ng} \mathrm{L}^{-1} \\
\mu \mathrm{g} \mathrm{g}^{-1}\end{array}$ & $\begin{array}{l}\min \\
\max \end{array}$ & $\begin{array}{c}0.04 \pm 0.02 \\
0.65 \pm 0.29 \\
1 \pm 0.3 \\
0.11 \pm 0.03\end{array}$ \\
\hline $\begin{array}{l}\text { Diet-borne contribution } \\
\text { waterborne contribution }\end{array}$ & {$[\mathrm{M}]_{\text {org }}$ ss } & $\begin{array}{l}\mu g^{-1} \\
\mu g^{-1} \\
\mu g^{-1} \\
\mu g^{-1} \\
\mu g^{-1}\end{array}$ & $\begin{array}{l}\min \\
\max \\
\min \\
\max \end{array}$ & $\begin{array}{l}0.035 \\
0.387 \\
0.023 \\
0.366 \\
0.013\end{array}$ \\
\hline
\end{tabular}


489 Using the range of all of the estimations from both methods, the value of $18 \%$ was set for

490 the AE. Green leaves (minimal hypothesis) were less Cd-contaminated than the decomposed

491 leaves sampled on gravels and sediments (maximal hypothesis), leading to two sets of

492 estimations for the diet-borne contribution to the overall Cd bioaccumulation (Table 2).

493 Simulations showed that Cd was bioaccumulated via both uptake pathways by the gammarids

494 and that the waterborne contribution $\left(0.013 \mu \mathrm{g} \mathrm{g}^{-1}\right)$ was low compared with the Cd diet-borne

495 contribution $\left(0.023-0.366 \mu \mathrm{g} \mathrm{g}^{-1}\right)$. The Cd diet-borne contribution was $66-94 \%$ of the

496 observed Cd body-burden even though we minimized the ingestion rate. As previously

497 hypothesized by Abel and Barlöcher (1988), the diet-borne uptake pathway significantly

498 contributed to the Cd bioaccumulation in freshwater gammarids.

499 The field-measured contamination of gammarids $\left(0.11 \pm 0.03 \mu \mathrm{g} \mathrm{g}^{-1}\right)$ is between the minimal

500 and maximal estimated values, indicating that G. pulex did not feed on only fresh or

501 decomposed leaves. This result highlights the importance of the behavior of gammarids in

502 metal diet-borne transfer. Moreover, the type of leaf may influence not only the

503 contamination of the food and the bioavailability in the gut (AE) but also the feeding strategy.

504 All of these parameters must be addressed to properly evaluate the importance of food quality

505 on the diet-borne contribution to metal transfer in gammarids, and they must be considered in 506 the definition of bioavailability.

507 4. Conclusion

A methodological adaptation of the pulse-chase feeding method using stable isotope

509 tracers was investigated to evaluate the $\mathrm{Cd}$ and $\mathrm{Cu}$ assimilation efficiencies of G. pulex

510 feeding on alder leaves. The use of collision cell technology in ICP-MS analysis significantly

511 improved the quantification of the chromium isotopes because it allows reliable net tracer 
$512{ }^{53} \mathrm{Cr}$ determinations in unlabeled and labeled samples. The pulse-chase feeding protocol

513 using metal stable isotopes is able to address the large modifications/adaptations that the

514 physiological characteristics of each species require. For the amphipod G. pulex feeding on

515 conditioned alder leaves, the $\mathrm{Cd}$ assimilation efficiency was evaluated within the range of 5 -

$51647 \%$. In contrast, the approach was not adapted to the copper AE estimation because of the

517 rapid regulation of $\mathrm{Cu}$ in gammarids. We also suspect analytical shortcomings with the ${ }^{65} \mathrm{Cu}$

518 determination in leaves, which might be overcome by adapting the digestion procedure to the

519 various matrices involved in the experiment and/or by using a higher mass resolution

520 analytical instrument.

521 Comparisons between the observed Cd body-burden in gammarids and the estimated diet-

522 borne contributions in field conditions provides evidence that the diet-borne uptake in situ

523 significantly contributes to the overall bioaccumulation of Cd. G. pulex is a promising study

524 organism for basic research on diet-borne availability of trace metals in an aquatic ecosystem

525 because it has a large food spectrum and adopts various types of feeding behavior within

526 different physical and ecological conditions.

528 Acknowledgements

529 The present study was funded by the PIREN-Seine Research project and the French

530 National Agency for Water and Aquatic Environments (Office National de l'Eau et des

531 Milieux Aquatiques). We extend thanks to Emmanuelle Uher for her technical assistance. We

532 thank the three anonymous reviewers for their constructive reviews. 


\section{References}

535 Abel, T., Bärlocher, F., 1988. Uptake of cadmium by Gammarus fossarum (Amphipoda) from food and

536 water. Journal of Applied Ecology 25, 223-231.

537 Ahlf, W., Drost, W., Heise, S., 2009. Incorporation of metal bioavailability into regulatory frameworks-

538 metal exposure in water and sediment. Journal of Soils and Sediments 9, 411-419.

539 Besse, J.P., Coquery M., Lopes C., Chaumot A., Budzinski H., Labadie P., Geffard O. 2013. Caged

540 Gammarus fossarum (Crustacea) as a robust tool for the characterization of bioavailable

541 contamination levels in continental waters: Towards the determination of threshold values. Water

542 Research 47, 650-660.

543 Bourgeault, A., Ciffroy, P., Garnier, C., Cossu-Leguille, C., Masfaraud, J.-F., Charlatchka, R., Garnier, 544 J.-M.. 2013. Speciation and bioavailability of dissolved copper in different freshwaters: comparison of 545 modelling, biological and chemical responses in aquatic mosses and gammarids. Science of the Total 546 Environment 452-453, 68-77

547 Cain, D., Croteau, M.-N., Luoma, S., 2011. Bioaccumulatiçon dynamics and exposure routes of Cd 548 and $\mathrm{Cu}$ among species of aquatic mayflies. Environmental Toxicology and Chemistry 30, 2532-2541.

549 Calow, P., Fletcher, C.R., 1972. A new radiotracer technique involving $14 \mathrm{C}$ and $51 \mathrm{Cr}$, for estimating 550 the assimilation efficiencies of aquatic, primary consumers. Oecologia 9, 155-170.

551 Correia, A.D., Pereira, A., Costa, M.H., Carrapiço, F., 2002. Functional anatomy of the midgut gland of 552 Gammarus locusta (Crustacea :a: Amphipoda). Journal of the Marine Biological Association U. K. 82, 553 201-204.

554 Coulaud, R., Geffard, O., Xuereb, B., Lacaze, E., Quéau, H., Garric, J., Charles, S., Chaumot, A., 555 2011. In situ feeding assay with Gammarus fossarum (Crustacea): Modelling the influence of 556 confounding factors to improve water quality biomonitoring. Water Research 45, 6417-6429.

557 Croteau, M.-N., Cain, D. J., Fuller. C.C. 2013. Novel and nontraditional use of stable isotope tracers to 558 study metal bioavailability from natural particles. Environmental Science and Tecnology 47, 34245593431.

560 Croteau, M.N., Luoma, S.N., 2005. Delineating copper accumulation pathways for the freshwater 561 bivalve Corbicula using stable copper isotopes. Environmental Toxicology and Chemistry 24, 28715622878. 
563 Croteau, M.N., Luoma, S.N., Pellet, B., 2007. Determining metal assimilation efficiency in aquatic

564 invertebrates using enriched stable metal isotope tracers. Aquatic Toxicology 83, 116-125.

565 Croteau, M.N., Luoma, S.N., Topping, B.R., Lopez, C.B., 2004. Stable metal isotopes reveal copper 566 accumulation and loss dynamics in the freshwater bivalve Corbucula. Environmental Science and 567 Technology 38, 5002-5009.

568 Davison, W., Zhang, H., 1994. In situ speciation measurements of trace components in natural waters 569 using thin film gels. Nature $367,546-548$.

570 Decho, A.W., Luoma, S.N., 1996. Flexible digestion strategies and trace metal assimilation in marine 571 bivalves. Limnology and Oceanography 41, 568-572.

572 Dedourge-Geffard O, Palais, F., Biagianti-Risboug, S., Geffard, O., Geffard, A., 2009. Effects of 573 metals on feeding rate and digestive enzymes in Gammarus fossarum: An in situ experiment. 574 Chemosphere 77, 1569-1576.

575 Felten, V., 2003. Effets de l'acidification des ruisseaux vosgiens sur la biologie, l'écologie et 576 l'écophysiologie de Gammarus fossarum Koch, 1835 (Crustacea Amphipoda) :): approche intégrée à 577 différents niveaux d'organisation. Sciences et Ingénierie des Ressources Procédés Produits 578 Environnement. Metz University, p. 340.

579 Fialho, L.L., Pereira, C.D., Nóbrega, J.A., 2011. Combination of cool plasma and collision-reaction 580 interface for correction of polyatomic interferences on copper signals in inductively coupled plasma 581 quadrupole mass spectrometry. Spectrochimica Acta Part B 66, 389-393

582 Fialkowski, W., Fialkowska, E., Smith, B. D., Rainbow, P. S., 2003. Biomonitoring survey of trace 583 metal pollution in streams of a catchment draining a zinc and lead mining area of Upper Silesia, 584 Poland using the amphipod Gammarus fossarum. International Review of Hydrobiology 88, 187-200.

585 Geffard, A, Sartelet, H, Garric, J, Biagianti-Risbourg, S, Delahaut, L, Geffard, O., 2010. Subcellular 586 compartmentalization of cadmium, nickel, and lead in Gammarus fossarum: comparison of 587 methods.Chemosphere $78,822-829$

588 Golding, L A, Borgmann, U, Dixon, D G, 2013. Cadmium bioavailability to Hyalella azteca from a 589 periphyton diet compared to an artificial diet and application of a biokinetic model. Aquatic Toxicology 590 126, 291-298.

591 Hammer, D., Nicolas, M., Andrey, D., 2005. Improved chromium determination in various food 592 matrices using dynamic reaction cell ICP-MS. Atomic Spectroscopy 26, 203-208. 
Khan, F.R., Irving, J.R., Bury, N.R., Hogstrand, C., 2011. Differential tolerance of two Gammarus pulex populations transplanted from different metallogenic regions to a polymetal gradient. Aquatic Toxicology 102, 95-103.

Kunz, PY, Kienle C, Gerhardt A (2010) Gammarus spp. in aquatic ecotoxicology and water quality assessment: toward integrated multilevel tests. Rev Environ Contam Toxicol 205, 1-76.

Lamberty, A., Muntau, H., 2005. The certification of the mass fraction of $\mathrm{As}, \mathrm{Cd}, \mathrm{Cr}, \mathrm{Cu}, \mathrm{Hg}, \mathrm{Mn}, \mathrm{Pb}$, Se and $\mathrm{Zn}$ in mussel tissue (Mytilus edulis) - ERM®-CE278. In: Research, S.a.T. (Ed.), DG Joint Research Centre, Institute for Reference Materials and Measurements, p. 49.

Lebrun, J., Perret, M., Geffard, A., Gourlay-Francé, C., 2012. Modelling copper bioaccumulation in Gammarus pulex and alterations of digestive metabolism. Ecotoxicology 21, 2022-2030.

Luoma, S.N., Johns, C., Fisher, N. S., Steinberg, N. A., Oremland, R.S., Relnfelder, J.R., 1992.

Determination of Selenium Bioavailability to a Benthic Bivalve from Particulate and Solute Pathways. Environmental Science and Technology 26, 485-491.

\section{Maltby, L., Clayton, S., Wood, R., McLoughlin, N., 2002. Evaluation of the Gammarus pulex in situ} feeding assay as a biomonitor of water quality: Robustness, responsiveness, and relevance. Environmental Toxicology and Chemistry, 361-368.

Nixon, D.E., al, e., 2000. Determination of Chromium in Serum and Urine. In: A.N. D6356 (Ed.), Perkin Elmer Instruments: Shelton, CT.

Pellet, B.J., Geffard, O., Lacour, C., Kermoal, T., Gourlay-Francé, C., Tusseau-Vuillemin, M.H., 2009. A model predicting waterborne cadmium bioaccumulation in Gammarus pulex : $x$ : the effects of dissolved organic ligands, calcium and temperature. Environmental Toxicology and Chemistry 28 , 2434-2442.

Roditi, H.A., Fisher, N.S., 1999. Rates and routes of trace element uptake in zebra mussels. Limnology and Oceanography 47, 1730-1749.

Schaller , J, Weiske, A, Mkandawire, M, Dudel, EG. 2010. Invertebrates control metals and arsenic sequestration as ecosystem engineers. Chemosphere 79:169-173

Schaller, J., Brackhage, C., Mkandawire, M., Dudel, E.G., 2011a. Metal/metalloid accumulation/remobilization during aquatic litter decomposition in freswater: a review. Science of the Total Environment 409: 4891-4898.

Schaller, J., Dharamshi, J., Dudel, E.G., 2011b. Enhanced metal and metalloid concentrations in the gut system comparing to remaining tissues of Gammarus pulex L. Chemosphere 83, 627-631. 
624

625

626

627

628

629

630

631

632

633

634

635

636

637

638

639

640

641

642

643

644

645

646

647

648

649

650

651

Schlekat, C.E., Decho, A.W., Chandler, G.T.L.a.O., 2000. 45(1): p. 11-21, 2000. Bioavailability of particle-associated silver, cadmium, and zinc to the estuarine amphipod Leptocheirus plumulosus through dietary ingestion. Limnology and Oceanography 45, 11-21.

Smokorowski, K.E., Lasenby, D.C., Evans, R.D., 1998. Quantifying the uptake and release of cadmium and copper by the opossum shrimp Mysis relicta preying upon the cladoceran Daphnia magna using stable isotope tracers. Canadian Journal of Fisheries and Aquatic Sciences 55, 909-916.

Sroda, S. Cossu-Leguille, C. 2011. Seasonal variability of antioxidant biomarkers and energy reserves in the freshwater gammarid Gammarus roeseli. Chemosphere 83, 538-544

Tanner, S.D., Baranov, V.I., Bandura, D.R., 2002. Reaction cells and collision cells for ICP-MS: a tutorial review. Spectrochimica Acta Part B: Atomic Spectroscopy 57, 1361-1452.

Tusseau-Vuillemin, M.H., Gourlay, C., Lorgeoux, C., Mouchel, J.M., Buzier, R., Gilbin, R., Seidel, J.L., Elbaz-Poulichet, F., 2007. Dissolved and bioavailable contaminants in the Seine river basin. Science of the Total Environment 375, 244-256.

Vellinger, C., Felten, V., Sornom, P., Rousselle, P., Beisel, J.-N., Usseglio-Polatera, P., 2012.

Behavioural and physiological responses of Gammarus pulex at three temperatures: individual and combined effects. PLoS ONE 7 (6), e39153, http://dx.doi.org/10.1371/journal.pone.0039153.

Wang, W.-X., Fisher, N.S., 1999. Assimilation efficiencies of chemical contaminants in aquatic invertebratess: a synthesis. Environmental Toxicology and Chemistry 18, 2034-2045.

Werner, I., 2000. Faecal pellet production by Arctic under-ice amphipods - transfer of organic matter through the ice/water interface. Hydrobiologia 426, 89-96.

(1)

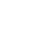

(1) 


\section{Supplemental information}

SI 1: The double-deck defecation chamber. 1. defecation chamber, 2. upper compartment (set aside in a beaker), 3. lower compartment, 4. Gammarids, 5.f eces, 6. toy (so they can hide)

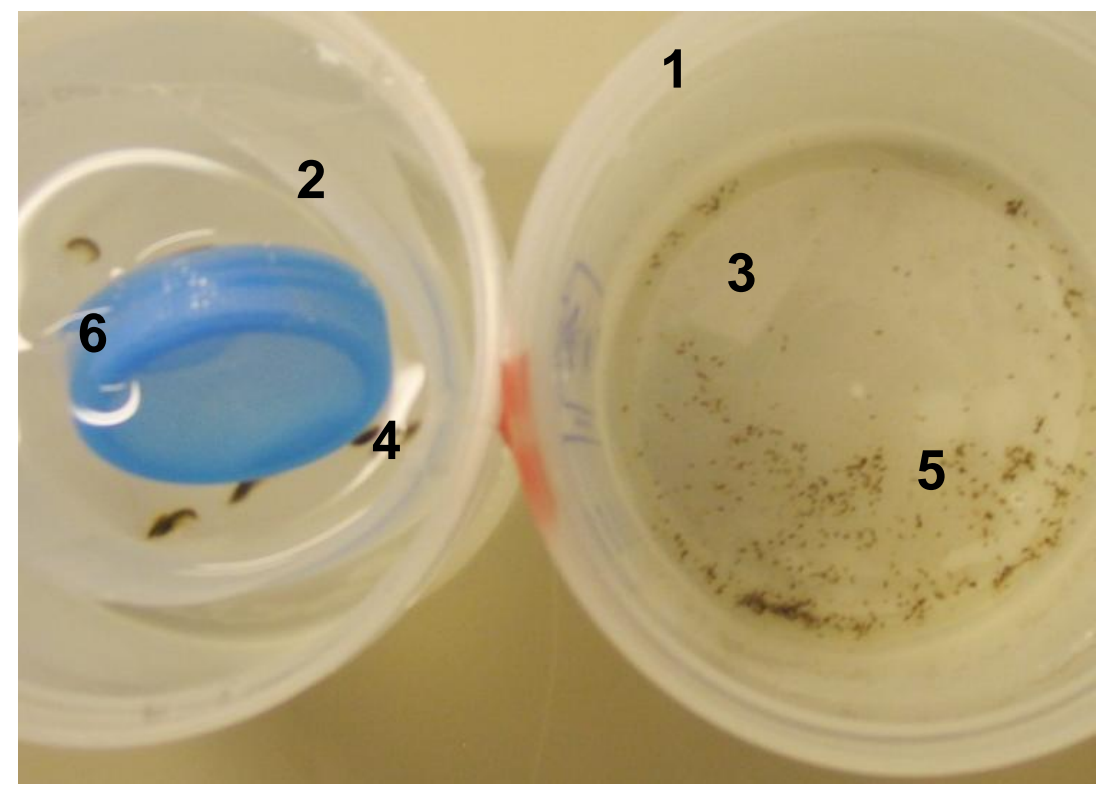

\section{SI 2: Calculation of the net tracer concentrations}

Net tracer concentrations in all samples were determined using the equations adapted from Croteau et al. (2004).

First, the $p^{m}$ ratio was determined for each tracer of atomic mass $m\left(m=53,65\right.$ and 106). $p^{m}$ is the relative ICP-MS signal intensity over the cumulative total intensities of all analyzed isotopes for the same element in calibration standards. This quantity is assumed to be constant in all non-spiked natural matrixes. For example for $\mathrm{Cd}, p^{106}$ was defined as: 


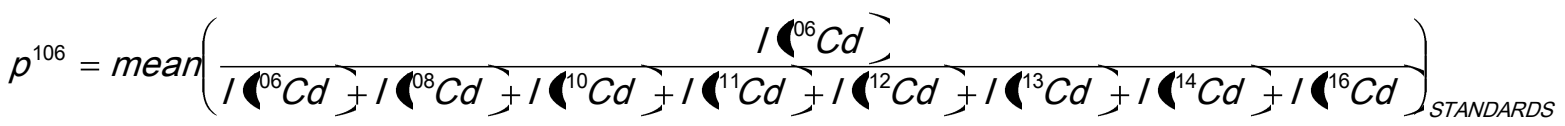
Equation 1

where $I\left({ }^{106} \mathrm{Cd}\right)$ is the ICP-MS signal intensity (counts) of ${ }^{106} \mathrm{Cd}$ in the calibration standards. The isotopes of atomic masses 50,52, 53, 54 were used for $\mathrm{Cr}$ and 63 and 65 for $\mathrm{Cu}$. We found $p^{106}=0.011, p^{53}=0.083$ and $p^{65}=0.33$.

Second, the total tracer concentration $\left(\left[{ }^{106} \mathrm{Cd}\right]\right)$ and the original tracer concentration $\left(\left[{ }^{106} \mathrm{Cd}\right]^{0}\right)$ were calculated in the samples.

The total tracer concentration was calculated as:

$$
{ }^{06} \mathrm{Cd}_{-}^{-}=p^{106} \cdot \mathbf{|}^{106} \mathrm{Cd}_{-}^{-} \quad \text { Equation 2 }
$$

where $\left[T^{106} \mathrm{Cd}\right]$ is the elemental Cd concentration inferred by the ICP-MS software from the ${ }^{106} \mathrm{Cd}$ signal intensity, in $\mu \mathrm{g} \mathrm{L}-1$. The original tracer concentration is the fraction of the concentration of the tracer expected in absence of a spike, given its relative abundance $p^{n}$. It was determined according to:

$$
\prod^{06} \mathrm{Cd}{ }_{-}^{\overline{0}}=p^{106} \cdot \mathbf{|}^{114} \mathrm{Cd}_{-}^{-} \quad \text { Equation } 3
$$

Lastly, the net tracer concentration $\left(\Delta\left[{ }^{106} \mathrm{Cd}\right]\right)$ was assessed by subtracting the contribution of the original tracer concentration from the total tracer concentration of the sample, which leads to:

$$
\Delta\left[{ }^{106} C d\right]=p^{106} \cdot\left(T^{106} C d\right]-\left[T^{114} C d\right]-\quad \text { Equation } 4
$$

where all quantities are expressed in $\mu \mathrm{g} \mathrm{L}^{-1}$ (in the sample). 
Same calculations were performed to calculate the net ${ }^{65} \mathrm{Cu}$ and ${ }^{53} \mathrm{Cr}$ concentration. The isotopes 52 and 63 were used to determine the original tracer concentration of $\mathrm{Cr}$ and $\mathrm{Cu}$, respectively.

SI 3: Table of mean values ( \pm standard deviation) of water chemistry parameters.

\begin{tabular}{l|l}
\hline conductivity $\left(\mu \sigma \mathrm{cm}^{-1}\right)$ & $1755 \pm 64$ \\
$\mathrm{pH}$ & $7.7 \pm 0.1$ \\
temperature $\left({ }^{\circ} \mathrm{C}\right)$ & $12.1 \pm 0.8$ \\
dissolved organic carbon $\left(\mathrm{mg} \mathrm{L}^{-1}\right)$ & 2.63 \\
\hline Anions and cations & $\mathrm{mg} \mathrm{L}^{-1}$ \\
$\mathrm{HCO}^{3-}$ & 263 \\
$\mathrm{Cl}^{-}$ & 23.5 \\
$\mathrm{NO}^{3-}$ & 0.95 \\
$\mathrm{SO}_{4}^{2-}$ & 10.6 \\
$\mathrm{Na}^{+}$ & 16.1 \\
$\mathrm{~K}^{+}$ & 5.49 \\
$\mathrm{Ca}^{2+}$ & 93.4 \\
$\mathrm{Mg}^{2+}$ & 6.9 \\
$\mathrm{NH}^{4+}$ & 0.46 \\
\hline
\end{tabular}

